\title{
Regulation of E3 ubiquitin ligase-1 (WWP1) by microRNA-452 inhibits cancer cell migration and invasion in prostate cancer
}

\author{
Yusuke Goto ${ }^{1,2}$, Satoko Kojima ${ }^{3}$, Akira Kurozumi ${ }^{1,2}$, Mayuko Kato ${ }^{1,2}$, Atsushi Okato ${ }^{1,2}$, Ryosuke Matsushita ${ }^{4}$, \\ Tomohiko Ichikawa ${ }^{2}$ and Naohiko Seki ${ }^{*}, 1$ \\ ${ }^{1}$ Department of Functional Genomics, Chiba University Graduate School of Medicine, Chiba, Japan; ${ }^{2}$ Department of Urology, \\ Chiba University Graduate School of Medicine, Chiba 260-8670, Japan; ${ }^{3}$ Department of Urology, Teikyo University Chiba Medical \\ Centre, Chiba 299-0111, Japan and ${ }^{4}$ Department of Urology, Graduate School of Medical and Dental Sciences, Kagoshima \\ University, Kagoshima 890-8520, Japan
}

Background: MicroRNA-224 (miR-224) and microRNA-452 (miR-452) are closely located on the human chromosome Xq28 region. miR-224 functions as a tumour suppressor by targeting tumour protein D52 (TPD52) in prostate cancer (PCa). Here, we aimed to investigate the functional significance of miR-452 in PCa cells.

\begin{abstract}
Methods: Functional studies of PCa cells were performed using transfection with mature miRNAs or siRNAs. Genome-wide gene expression analysis, in silico analysis, and dual-luciferase reporter assays were applied to identify miRNA targets. The association between miR-452 levels and overall patient survival was estimated by the Kaplan-Meier method.

Results: Expression of miR-452 was significantly downregulated in PCa tissues. Transfection with mature miR-452 inhibited the migration and invasion of PCa cells. Kaplan-Meier survival curves showed that low expression of miR-452 predicted a short duration of progression to castration-resistant PCa. WW domain-containing E3 ubiquitin protein ligase-1 (WWP1) was a direct target of miR-452, and knockdown of WWP1 inhibited the migration and invasion of PCa cells. WWP1 was upregulated in PCa clinical specimens.
\end{abstract}

Conclusions: Regulation of the miR-452-WWP1 axis contributed to PCa cell migration and invasion, and elucidation of downstream signalling of this axis will provide new insights into the mechanisms of PCa oncogenesis and metastasis.

Prostate cancer $(\mathrm{PCa})$ is the most frequently diagnosed cancer and the second leading cause of cancer death among men in developed countries (Siegel et al, 2015). Multiple therapeutic options are available for patients with early stage $\mathrm{PCa}$, and its prognosis is relatively favourable (Heidenreich et al, 2014a). In contrast, patients with advanced-stage $\mathrm{PCa}$ are initially treated with androgen deprivation therapy (ADT); however, their cancers eventually become resistant to ADT and progress to castrationresistant PCa (CRPC; Attard et al, 2016). Although several clinical trials for CRPC have been carried out, resulting in the availability of novel chemotherapeutic agents, these treatments provide limited benefits and are not considered curative (Heidenreich et al, 2014b; Crawford et al, 2015). Therefore, identification of effective biomarkers for detection of CRPC and understanding the molecular mechanisms of androgen-independent signalling and metastatic signalling pathways underlying PCa using current genomic approaches would help to improve therapies for and prevention of the disease.

MicroRNAs (miRNAs) are endogenous small RNA molecules (19-22 bases in length) that regulate protein-coding/non-proteincoding gene expression by translational repression or mRNA cleavage (Bartel, 2004). MicroRNAs are bioinformatically predicted

*Correspondence: Dr N Seki; E-mail: naoseki@faculty.chiba-u.jp

Received 7 February 2016; revised 8 March 2016; accepted 11 March 2016; published online 12 April 2016

(c) 2016 Cancer Research UK. All rights reserved 0007-0920/16 
to regulate more than one-third of the protein-coding genes in the human genome (Lewis et al, 2005; Friedman et al, 2009). Therefore, miRNAs act as fine-tuning regulators in almost all biological processes (Bartel, 2009). As for human cancers, a growing body of evidence has indicated that normal RNA regulatory networks can be disrupted by the aberrant expression of tumour-suppressive or oncogenic miRNAs in cancer cells (Garzon et al, 2009). Identification of aberrantly expressed miRNAs and novel network searches beginning from tumour-suppressive or oncogenic miRNAs has facilitated elucidation of the molecular mechanisms of cancer initiation, development, and metastasis.

Identification of aberrantly expressed miRNAs is the first step towards elucidating miRNA-based regulatory networks in $\mathrm{PCa}$ cells. Based on this, we constructed the miRNA expression signatures of PCa and CRPC using clinical specimens and identified tumour-suppressive miRNAs regulating novel oncogenic pathways (Fuse et al, 2012; Goto et al, 2015a). Interestingly, several miRNAs were found to be located within close proximity in the human genome, constituting a cluster of miRNAs. Our miRNA expression signatures of PCa showed that several clustered miRNAs were downregulated in cancer cells (Goto et al, 2015b). Focusing on the clustered miRNAs in our signatures, we have shown that the clustered miRNAs $m i R-1 / 133 a$, miR-143/145, $m i R-$ $23 \mathrm{~b} / 27 \mathrm{~b} / 24-1$, and $m i R-221 / 222$ function as tumour suppressors by targeting several oncogenic genes or pathways in PCa cells (Kojima et al, 2012; Goto et al, 2014a; Kojima et al, 2014; Goto et al, 2015a).

In this study, we focused on $m i R-452$, which forms a cluster with $m i R-224$ on the human chromosome Xq28 region. Our previous study revealed that $m i R-224$ inhibits cancer cell migration and invasion by directly regulating oncogenic tumour protein D52 (TPD52) in PCa cells (Goto et al, 2014b). However, the functional roles of miR-452 in PCa cells are still unknown. The aim of this study was to investigate the functional significance of $m i R-452$ and the novel oncogenic pathways regulated by this miRNA in PCa cells.

We found that restoration of $m i R-452$ significantly inhibited cancer cell migration and invasion. WW domain-containing E3 ubiquitin protein ligase-1 (WWP1) was one of multiple targets of $m i R-452$ regulation in $\mathrm{PCa}$ cells and it was directly regulated by $m i R-452$ in PCa cells. Moreover, silencing of WWP1 inhibited the migration and invasion of PCa cells. Discovery of the molecular targets and pathways regulated by tumour-suppressive miR-452 will provide insights into the potential molecular mechanisms of $\mathrm{PCa}$ oncogenesis and metastasis, and will facilitate the development of novel diagnostic and therapeutic strategies for the treatment of the disease.

\section{MATERIALS AND METHODS}

Patients and clinical prostate specimens. Prostate specimens were obtained from patients admitted to Teikyo University Chiba Medical Centre Hospital from 2008 to 2013. Ninety patients with elevated prostate-specific antigen (PSA) levels underwent transrectal prostate needle biopsies. From the collected samples, $54 \mathrm{PCa}$ tissues and 36 normal prostate tissues (non-PCa) were used. The patients' characteristics are summarised in Supplementary Table 1. For pathological verification, we obtained two needle biopsy specimens from the same region as used in this study, and one was pathologically proven to contain no cancerous tissue (designated the non-PCa specimens). Before prostate biopsies, written consent for tissue donation was obtained from each patient. The protocol was approved by the Institutional Review Board of Chiba University and Teikyo University. The definition of CRPC described by the European Association of Urology was used in this study (Heidenreich et al, 2014b).
Cell culture. Human PCa cells (PC3 and DU145 cells) were obtained from the American Type Culture Collection (Manassas, VA, USA) and maintained in RPMI-1640 medium supplemented with $10 \%$ foetal bovine serum in a humidified atmosphere of $5 \% \mathrm{CO}_{2}$ and $95 \%$ air at $37^{\circ} \mathrm{C}$.

RNA isolation. Total RNA was isolated using TRIzol reagent (Invitrogen, Carlsbad, CA, USA) according to the manufacturer's protocol. The quality of RNA was confirmed using an Agilent 2100 Bioanalyzer (Agilent Technologies, Santa Clara, CA, USA) as described previously (Goto et al, 2014a; Goto et al, 2015a; Kurozumi et al, 2016).

Quantitative real-time reverse transcription polymerase chain reaction (RT-qPCR). PCR was performed as previously described (Goto et al, 2014a; Goto et al, 2015a; Kurozumi et al, 2016). The expression levels of miR-224 (Assay ID: 002099) and miR-452 (Assay ID: 002329) were analysed by TaqMan RT-qPCR (TaqMan MicroRNA Assay; Applied Biosystems) and normalised to RNU48 (Assay ID: 001006). TaqMan probes and primers for WWP1 (P/N: Hs00366931_g1) and GUSB (P/N: Hs00939627_m1) as an internal control were obtained from Applied Biosystems (Assay-On-Demand Gene Expression Products).

Transfection with mature miRNA and small-interfering RNA (siRNA). The following mature miRNA species were used in this study: Ambion Pre-miR miRNA precursor for $h s a-m i R-452$ (product ID: PM12509). The following siRNAs were used: Stealth Select RNAi siRNA; si-WWP1 (cat no. HSS117118 and HSS117119; Invitrogen); and negative control miRNA/siRNA (P/N: AM17111, Applied Biosystems). RNAs were incubated with OPTI-MEM (Invitrogen) and Lipofectamine RNAiMAX reagent (Invitrogen). The transfection procedures and transfection efficiencies of miRNA in PC3 and DU145 cells were reported previously (Goto et al, 2014a; Goto et al, 2015a; Kurozumi et al, 2016).

Cell proliferation, migration, and invasion assays. Cell proliferation was determined by XTT assay using a Cell Proliferation Kit II (Roche Applied Sciences, Tokyo, Japan). Cell migration activity was analysed using uncoated Transwell polycarbonate membrane filters. Cell invasion was evaluated using modified Boyden chambers containing Transwell-precoated Matrigel membrane filter inserts. These assays were carried out as previously described (Goto et al, 2014a; Goto et al, 2015a; Kurozumi et al, 2016).

Genome-wide gene expression and in silico analyses for the identification of genes regulated by $m i R-452$. We performed a combination of in silico and genome-wide gene expression analyses. First, genes regulated by $m i R-452$ were listed using the TargetScan database. Next, to identify upregulated genes in PCa, we analysed a publicly available gene expression data set in GEO (accession number: GSE29079). Finally, we carried out genomewide gene expression analysis using miR-452 transfectants of PC3 and DU145 cells. A SurePrint G3 Human GE 60K Microarray (Agilent Technologies) was used for expression profiling of miRNA transfectants in comparison with negative control miRNA transfectants. Finally, downregulated mRNAs containing $m i R-452$ target sites were listed as putative target genes.

Western blotting. Immunoblotting was performed with rabbit anti-WWP1 antibodies (1:700, ab43791; Abcam), and antiGAPDH antibodies $(1: 1000$, ab8245; Abcam) were used as an internal loading control. Membranes were washed and incubated with anti-rabbit IgG horseradish peroxidase-linked antibodies (7074; Cell Signaling Technology, Danvers, MA, USA). Complexes were visualised with Clarity Western ECL Substrate (Bio-Rad, Hercules, CA, USA), as described in our previous studies (Goto et al, 2014a; Goto et al, 2015a; Kurozumi et al, 2016). 
Plasmid construction and dual-luciferase reporter assay. Partial wild-type sequences of the WWP1 $3^{\prime}$ untranslated region (UTR) or those with deleted miR-452 target sites (position 150-156 of the WWP1 $3^{\prime}$ UTR) were inserted between the XhoI-PmeI restriction sites in the $3^{\prime}$ UTR of the hRluc gene in the psiCHECK-2 vector (C8021; Promega, Madison, WI, USA). The protocol for vector construction was described previously (Goto et al, 2014a; Goto et al, 2015a; Kurozumi et al, 2016).

Immunohistochemistry. A tissue microarray containing a total of 77 prostate specimens was used (Supplementary Table 2). The tissue microarray was obtained from Provitro (Berlin, Germany; Cat \#401 2209, Lot \#146.1 P020212, 26-46). Detailed information on all cancer specimens can be found at http://www.provitro.com/ fileadmin/provitro-data/TMA/4012209.pdf. Immunostaining was evaluated using a previously described scoring method (Kojima et al, 2012). Tissue microarray was immunostained with an UltraVision Detection System (Thermo Scientific, Fremont, CA, USA) following the manufacturer's protocol. Primary rabbit polyclonal antibodies against WWP1 (1:200, ab43791; Abcam) were used for immunochemistry. The slides were treated with biotinylated goat antibodies (Histofine SAB-PO kit; Nichirei, Tokyo, Japan).
Statistical analysis. The relationships between two groups and the numerical values obtained by RT-qPCR were analysed using Mann-Whitney $U$ tests. Spearman's rank test was used to evaluate the correlations between the expression of $m i R-224$ and $m i R-452$. The relationships among $>3$ variables and numerical values were analysed using the Bonferroni-adjusted Mann-Whitney $U$ test. Survival analysis was analysed by the Kaplan-Meier method and log-rank test, using Stat Mate software (version 4.01, ATMS Co., Tokyo, Japan). All other analyses were performed using Expert StatView (version 5, SAS Institute Inc., Cary, NC, USA).

\section{RESULTS}

Expression levels of $m i R-224$ and $m i R-452$ in PCa specimens and cell lines. Database analysis demonstrated that these miRNAs were closely located on human chromosome Xq28 within 1000 base pairs, forming a cluster (Figure 1A).

We analysed the expression levels of $m i R-224$ and $m i R-452$ in non-PCa $(n=36)$ and PCa $(n=54)$ clinical specimens. The median PSA level of patients with non-PCa specimens was $7.315 \mathrm{ng} / \mathrm{ml}$ (range, $4.3-35.5 \mathrm{ng} \mathrm{ml}^{-1}$ ). On the other hand, PSA levels in patients with $\mathrm{PCa}$ were high, with a median of

A
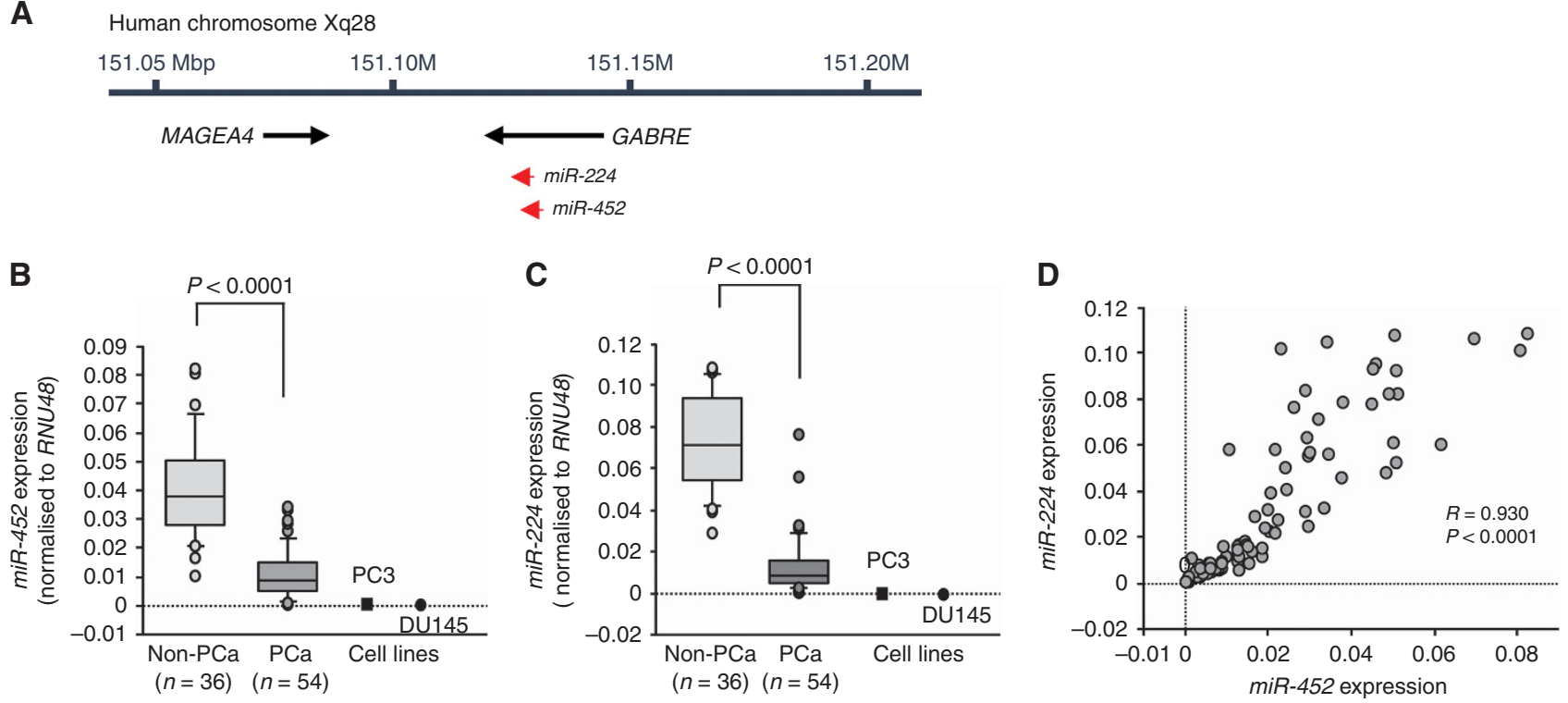

E

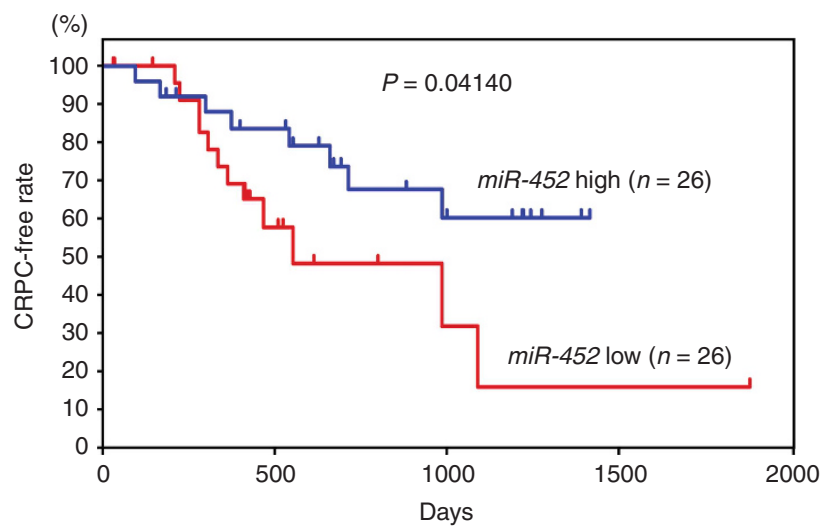

$\mathbf{F}$

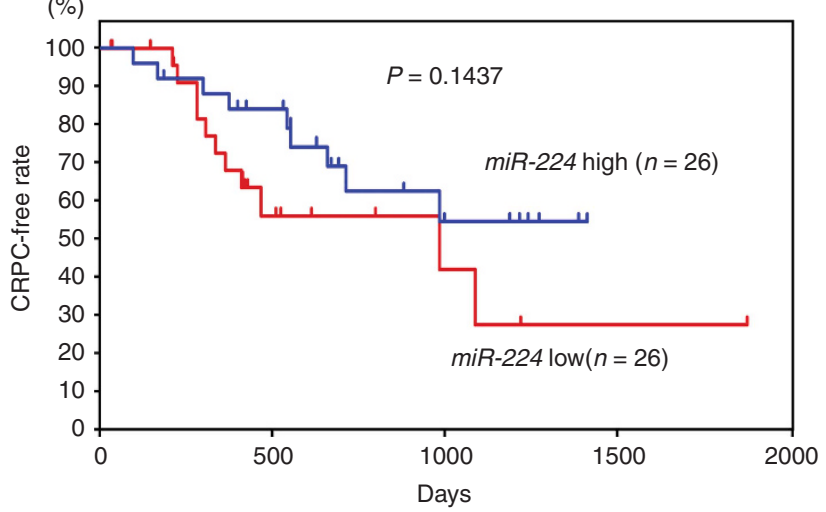

Figure 1. Location and expression levels of clustered miR-224/452 and its associations with CRPC progression-free interval. (A) Location of the miR-224/452 cluster in the human genome. (B) Expression levels of miR-452 in PCa clinical specimens and cell lines. RNU48 was used for normalisation. (C) Expression levels of miR-224 in PCa clinical specimens. RNU48 was used for normalisation. (D) Correlations among the relative expression levels of miR-224 and miR-452. (E) Kaplan-Meier analysis for expression level of miR-452 and CRPC-free rate. (F) Kaplan-Meier analysis for expression level of miR-224 and CRPC-free rate. 
$212 \mathrm{ng} \mathrm{ml}^{-1}$ (range, $3.45-3750 \mathrm{ng} \mathrm{ml}^{-1}$ ). Forty-four patients with PCa had advanced disease with metastasis to lymph nodes, bone, or other sites (Supplementary Table 1).

The expression levels of $m i R-224$ and $m i R-452$ were significantly downregulated $(P<0.0001)$ in $\mathrm{PCa}$ tissues compared with nonPCa tissues (Figure 1B and C). Furthermore, Spearman's rank test showed positive correlations between the expression of $m i R-224$ and $m i R-452(R=0.930$ and $P<0.0001$; Figure $1 D)$.

We have previously published data showing the functional significance of miR-224 and its target TPD52 (Goto et al, 2014b). Therefore, in this study, we performed additional analyses of $m i R-452$.

Associations between the expression levels of $m i R-452$ and CRPC progression in PCa tissues. Among 54 patients with $\mathrm{PCa}$, 52 underwent ADT with luteinising hormone-releasing hormone agonist and anti-androgens. A total of 20 patients progressed to CRPC despite combined androgen blockade (Supplementary Table 1). The risk of progression to CRPC was evaluated in patients with high $v s$ low $m i R-452$ expression. Low expression of $m i R-452$ was associated with shorter progression-free interval $(P=0.0414$; Figure $1 \mathrm{E})$. However, there was no association between expression level of $m i R-224$ and progression-free interval $(P=0.1437$; Figure $1 \mathrm{~F})$.

Effects of restoring $m i R-452$ expression on cell proliferation, migration, and invasion in PC3 and DU145 cells. To investigate the functional roles of $m i R-452$, we performed gain-of-function studies using miRNA transfection in PC3 and DU145 cells. Cell proliferation was not inhibited in $m i R-452$ transfectants in comparison with mock- or miR-control-transfected PC3 cells (Figure 2A). However, $m i R-452$ transfection significantly inhibited cell migration as compared with mock- or miR-control-transfected PC3 and DU145 cells $(P<0.0001$; Figure 2B). Similarly, Matrigel invasion assays demonstrated that cell invasion activity was significantly inhibited in $m i R-452$ transfectants in comparison with mock- or miR-control-transfected PC3 and DU145 cells $(P<0.0001 ;$ Figure 2C). The representative micrographs of migration and invasion assays are shown in Supplementary Figure 1.

To investigate the synergistic effects of $m i R-224$ and $m i R-452$, we performed migration assay with cotransfection of $m i R-224$ and $m i R-452$ in PC3, but they did not show synergistic effects of these miRNAs transfection (Supplementary Figure 2).

Identification of target genes regulated by miR-452 in PCa. We performed in silico and microarray analysis to identify target genes of $m i R-452$. First, the TargetScan programme showed that 3161 genes had putative target sites for $m i R-452$ in their $3^{\prime}$ UTRs. Next, we investigated the expression statuses of these genes in PCa clinical specimens and examined gene expression profiles in the GEO database (GEO accession number: GSE29079) to evaluate upregulated genes in PCa specimens. Among the 3161 putative target genes of the $m i R-452,704$ genes were significantly upregulated in $\mathrm{PCa}$ specimens compared with non-PCa tissues $\left(\log _{2}\right.$ ratio $\left.>0.1\right)$. Finally, we performed genome-wide gene expression analysis using PC3 and DU145 cells (GEO accession number: GSE56243). Ten genes downregulated ( $\log _{2}$ ratio $<-0.2$ ) by $m i R-452$ transfection were identified as putative target genes (Table 1). Methods for $m i R-452$ targets selection are shown in Supplementary Figure 3. Among these genes, WWP1 was the most highly upregulated in PCa specimens; therefore, we selected WWP1 for further studies.

WWP1 was a direct target of $\mathbf{m i R}-\mathbf{4 5 2}$ in PCa cells. To determine whether miR-452 restoration influences WWP1 expression, realtime RT-qPCR and western blotting were performed using PC3 and DU145 cells. WWP1 mRNA and WWP1 protein were significantly downregulated by $m i R-452$ transfection as compared
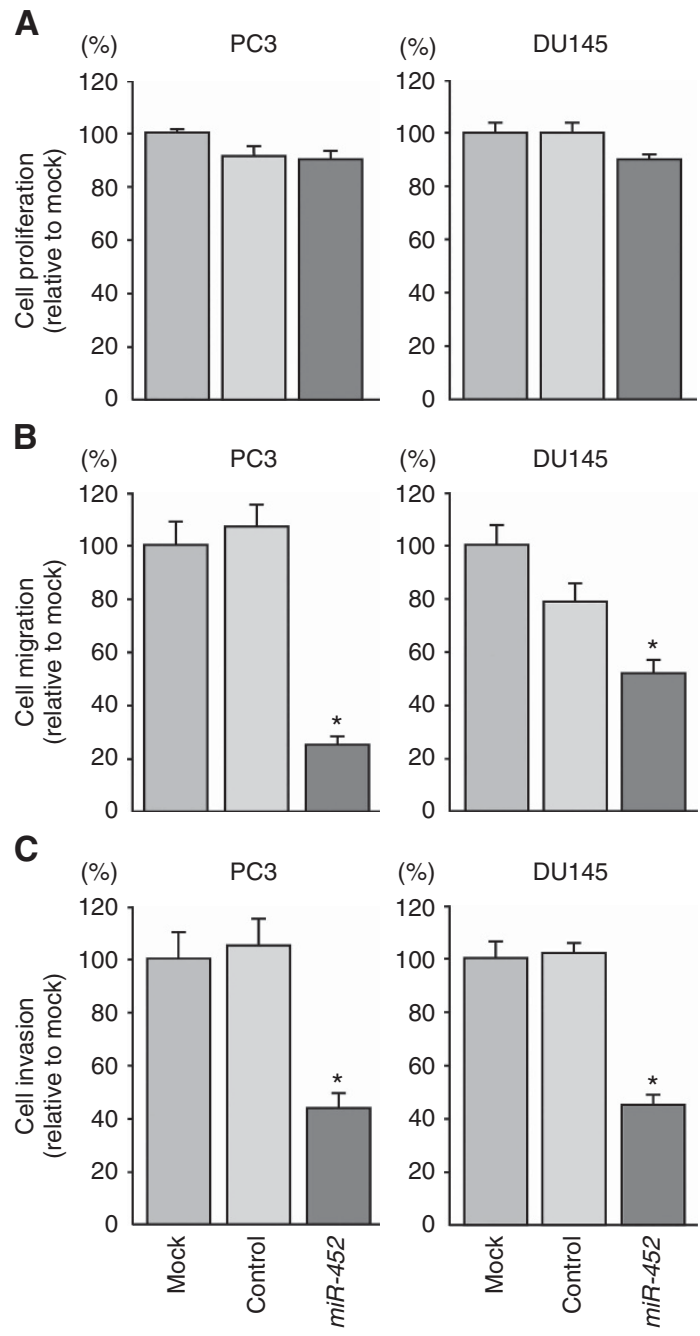

Figure 2. Functional analysis of miR-452 transfection in PC3 and DU145 cells. (A) Cell proliferation was determined $72 \mathrm{~h}$ after transfection with miR-452 using XTT assays. (B) Cell migration activity was determined $48 \mathrm{~h}$ after transfection with miR-452 using uncoated Transwell polycarbonate membrane filters. (C) Effects of miR-452 transfection on cell invasion in PC3 and DU145 cells. Cell invasion activity was determined $48 \mathrm{~h}$ after transfection with miR-452 using Matrigel invasion assays. ${ }^{\star} P<0.0001$. The bars indicate s.d.'s.

with that in mock- or miR-control-transfected cells $(P<0.0001$; Figure $3 \mathrm{~A}$ and $\mathrm{B}$ ).

Next, we carried out luciferase reporter assays to demonstrate whether $m i R-452$ directly bound to the $3^{\prime}$ UTR of WWP 1 . The TargetScan database predicted that $m i R-452$ bound at position $150-156$ in the $3^{\prime}$ UTR of WWP1. We used vectors encoding a partial wild-type sequence of the $3^{\prime}$ UTR of WWP1 mRNA, including the predicted $m i R-452$ target site, or a vector lacking the $m i R-452$ target site. We found that the luminescence intensity was significantly reduced by cotransfection with $m i R-452$ and the vector carrying the wild-type $3^{\prime}$ UTR of WWP1. In contrast, the luminescence intensity was not repressed when the seed sequence of the target site was deleted from the vectors $(P<0.0001$; Figure 3C).

Effects of silencing WWP1 on cell proliferation, migration, and invasion in PCa cell lines. To investigate the functional role of $W W P 1$, we performed loss-of-function studies using si-WWP1 transfectants. First, we evaluated the knockdown efficiency of si-WWP1 transfection in PC3 and DU145 cells. RT-qPCR and 
Table 1. Downregulated genes in miR-452 transfectants and upregulated genes in GEO database

\begin{tabular}{|c|c|c|c|c|c|c|c|}
\hline $\begin{array}{l}\text { Entrez } \\
\text { gene ID }\end{array}$ & Symbol & Gene name & Location & $\begin{array}{l}\text { GEO fold } \\
\text { change }\end{array}$ & $\begin{array}{l}\text { PC3 miR-452 } \\
\text { transfectant }\end{array}$ & $\begin{array}{l}\text { DU145 miR-452 } \\
\text { transfectant }\end{array}$ & Average \\
\hline 7464 & CORO2A & Coronin, actin binding protein, $2 \mathrm{~A}$ & $9 q 22.33$ & 0.608958 & -0.4396 & -0.2172 & -0.3284 \\
\hline 9878 & TOX4 & TOX high mobility group box family member 4 & $14 q 11.2$ & 0.44237 & -0.2266 & -0.2445 & -0.2355 \\
\hline 7586 & ZKSCAN1 & Zinc finger with KRAB and SCAN domains 1 & $7 q 22.1$ & 0.4397794 & -0.2062 & -0.2153 & -0.2107 \\
\hline 2768 & GNA12 & $\begin{array}{l}\text { Guanine nucleotide binding protein (G protein) alpha } \\
12\end{array}$ & 7p22.3 & 0.2904589 & -0.2326 & -0.2316 & -0.2321 \\
\hline 3149 & HMGB3 & High mobility group box 3 & $\mathrm{Xq} 28$ & 0.249856 & -0.4748 & -0.2121 & -0.3434 \\
\hline 79034 & C7orf26 & Chromosome 7 open reading frame 26 & $7 \mathrm{p} 22.1$ & 0.1855203 & -0.2318 & -0.2025 & -0.2172 \\
\hline 8087 & FXR1 & Fragile $\mathrm{X}$ mental retardation, autosomal homologue 1 & $3 q 26.33$ & 0.1841815 & -0.4090 & -0.2704 & -0.3397 \\
\hline
\end{tabular}
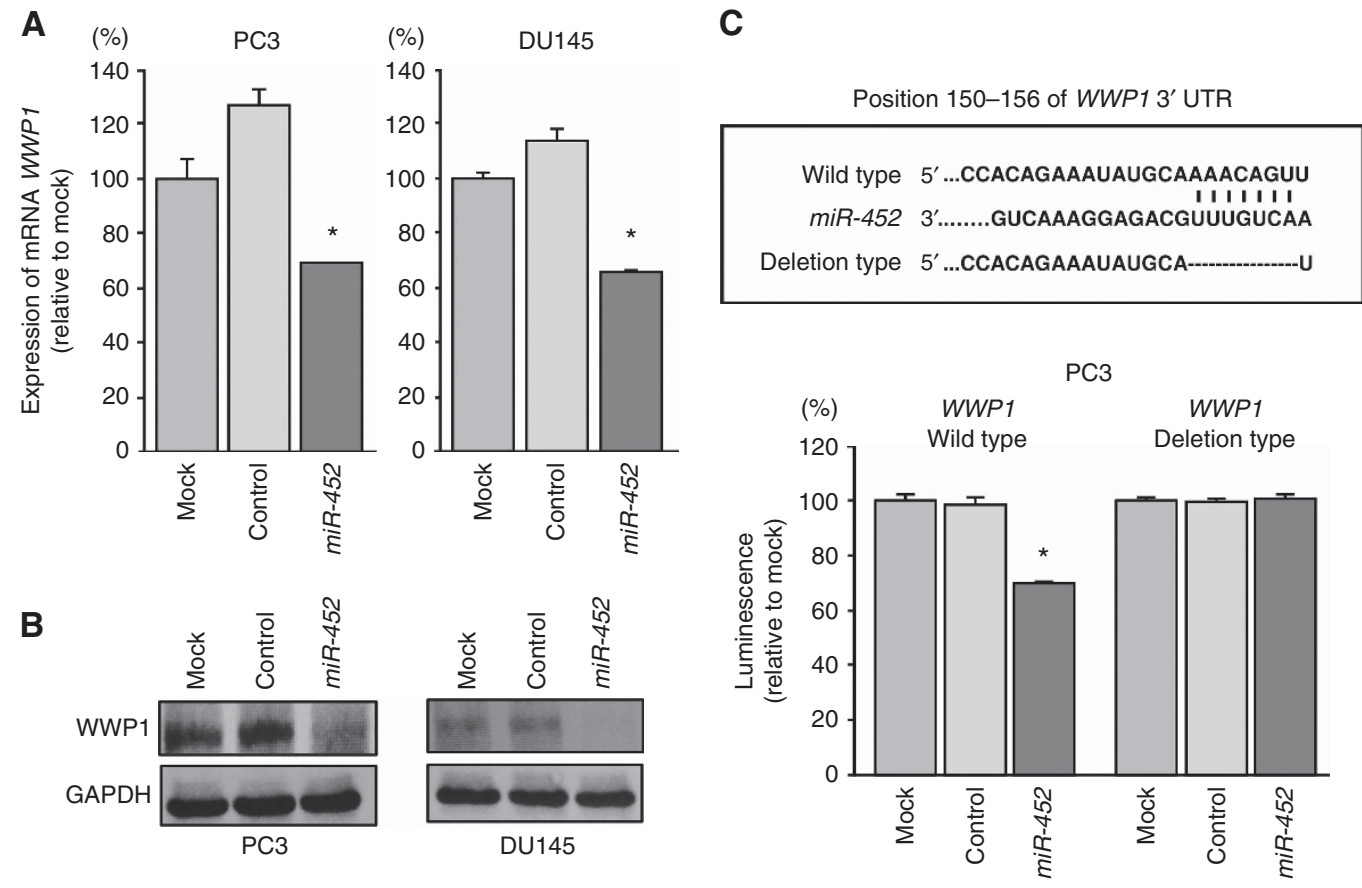

Figure 3. Downregulation of WWP1 expression by miR-452 in PC3 and DU145 cells. (A) WWP1 mRNA expression $72 \mathrm{~h}$ after transfection with miR-452. GUSB was used as an internal control. (B) WWP1 protein expression $72 \mathrm{~h}$ after transfection with miR-452. GAPDH was used as a loading control. (C) miR-452 binding sites in WWP1 mRNA. Luciferase reporter assays were carried out using a vector encoding the putative miR-452 target site in the WWP1 3'-UTR (position 150-156) for wild-type and deletion constructs. ${ }^{\star} P<0.0001$. The bars indicate s.d.'s.

western blotting indicated that si-WWP1 transfection effectively downregulated WWP1 mRNA and WWP1 protein expression in PC3 and DU145 cells (Supplementary Figure 4A and B).

In functional assays, cell proliferation was not inhibited by transfection with si-WWP1 in comparison with mock- or si-control-transfected cells (Figure 4A). However, cell migration and invasion assays demonstrated that cancer cell migration and invasion activity were significantly inhibited by si-WWP1 transfection in comparison with mock- or si-control-transfected PC3 and DU145 cells $(P<0.0001$; Figure 4B and C). The representative micrographs of migration and invasion assays are shown in Supplementary Figure 1.

Pathways modulated by knockdown of WWP1 in PCa cells. To further investigate which genes and pathways are modulated by miR-452-WWP1 signalling, we performed genome-wide gene expression analysis using si-WWP1 in PC3. After transfection with si-WWP1 in PC3 cells, we selected significantly upregulated or downregulated genes by si-WWP1 transfection (Log2 [siWWP1/mock] $>0.5$ or $\log 2[$ si-WWP1/mock] $<-1.0)$ and analysed by KEGG pathways using GeneCodis software (http:// genecodis.cnb.csic.es/). Table 2 indicates significantly upregulated and downregulated pathways by knockdown of WWP1. A variety of signalling pathways, including the ErbB signalling pathway and transforming growth factor (TGF)-beta signalling pathway, were significantly upregulated by si-WWP1. Pathways related to cancer cell migration and invasion, such as 'ECM-receptor interaction' and 'cell adhesion molecules', were significantly downregulated by knockdown of WWP1 in PC3 cells.

Expression of WWP1 in clinical PCa specimens. To gain further insights into whether upregulation of WWP1 was correlated with cancerous or precancerous regions, we used tissue microarrays. Immunostaining was evaluated according to a previously described scoring method. Each case was scored on the basis of the intensity and area of staining. A total of $57 \mathrm{PCa}$ samples, 10 prostatic 
A

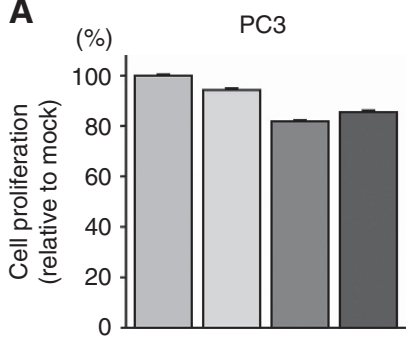

B

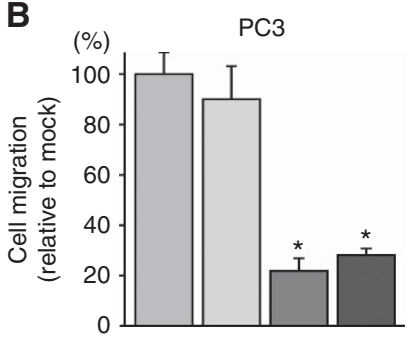

C

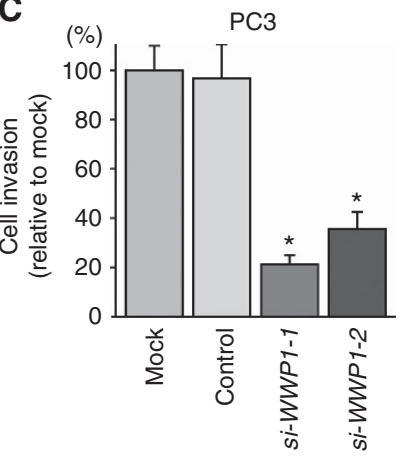

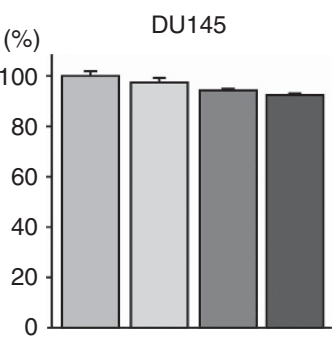
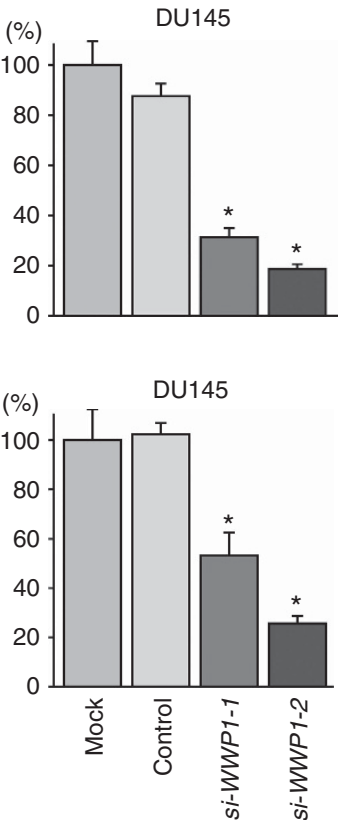

D

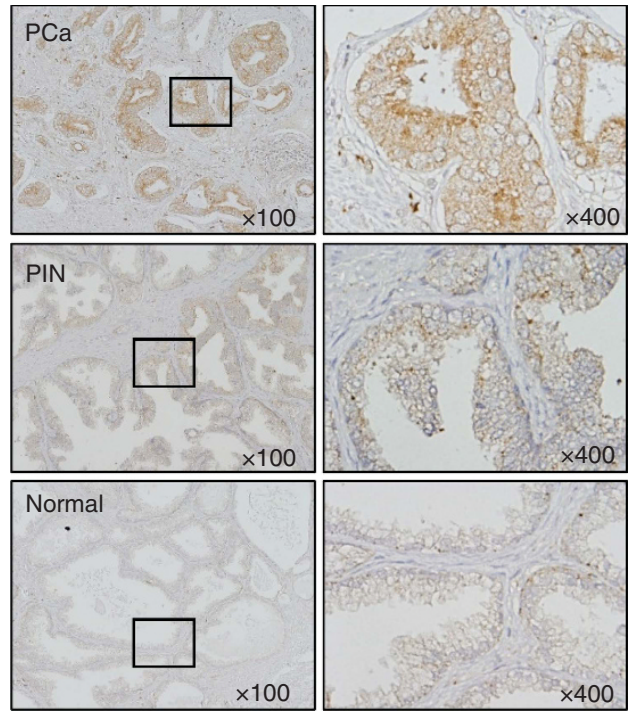

E

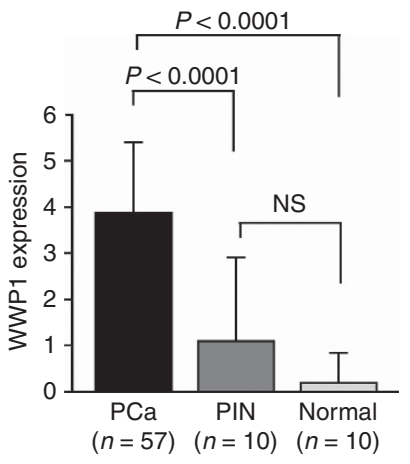

Figure 4. Effects of WWP1 knockdown on cell proliferation, migration, and invasion in PCa cells and expression of WWP1 in clinical PCa specimens. (A) Cell proliferation was determined by XTT assays. (B) Cell migration activity was determined using uncoated Transwell polycarbonate membrane filters. (C) Cell invasion activity was determined by Matrigel invasion assays. (D) Representative image of IHC of WWP1 in the tissue microarray. (E) WWP1 was upregulated in PCa compared with PIN and normal tissue in the tissue microarray. ${ }^{\star} P<0.0001$. The bars indicate s.d.'s.

intraepithelial neoplasia (PIN) samples, and 10 normal prostate samples were used to analyse WWP1 expression in this study (Supplementary Table 2).

Expression of WWP1 was significantly higher in clinical PCa specimens than in normal prostate specimens $(P<0.0001$; Figure $4 \mathrm{D}$ and E). Furthermore, expression of WWP1 was significantly higher in clinical $\mathrm{PCa}$ specimens than in PIN specimens $(P<0.0001$; Figure $4 \mathrm{D}$ and E). GEO database analysis (accession number GDS2545) showed that WWP1 expression in metastatic PCa was significantly higher than primary PCa (Supplementary Figure 5).

\section{DISCUSSION}

A substantial body of evidence suggests that aberrantly expressed miRNAs disrupt the tightly regulated RNA networks in cancer cells (Garzon et al, 2009; Iorio and Croce, 2012). Currently, these destructive events are thought to cause to cancer cell initiation, progression, and metastasis. Therefore, studies of differentially expressed miRNAs in cancer cells should provide important information regarding the molecular mechanisms underlying oncogenesis and metastasis. To date, 2578 human mature miRNAs have been annotated in the publicly available database (miRBase, release 21; http://www.mirbase.org/). MicroRNAs are often associated in clusters in the genome, and several studies have focused on the functional role of clustered miRNAs in human cancers (Mendell, 2008; Goto et al, 2015b). In the human genome, 429 human miRNAs have been found to be clustered at 144 sites, with inter-miRNA distances of $<5000 \mathrm{bp}$ (miRBase, release 21). The biological significance of clustered miRNAs in the human genome is still largely unknown. We have focused on downregulated clustered miRNAs in cancer cells based on the miRNA expression signatures and investigated the functional significance of these miRNAs (Kojima et al, 2012; Kojima et al, 2014; Goto et al, 2014a; Goto et al, 2015a).

In this study, we focused on $m i R-452$ because $m i R-224$ and $m i R$ 452 are located in close proximity on the human chromosome Xq28 region, representing a miRNA cluster. Our previous study showed that $m i R-224$ acts as a tumour suppressor by targeting oncogenic TPD52 (Goto et al, 2014b). Our present data showed that restoration of $m i R-452$ significantly inhibited cancer cell migration and invasion, indicating that $m i R-452$ also acts as a tumour suppressor in PCa cells. The tumour-suppressive role of $m i R-452$ has been reported in gliomas, targeting stemness regulators, such as Bmi-1, LEF1 and TCF4, and inhibiting stemlike traits (Liu et al, 2013). Furthermore, $m i R-452$ has been shown to function as a prognosis marker for overall survival in patients with glioma. It is well known that hypermethylation of promoter 
Table 2. Significantly upregulated/downregulated pathways modulated by knockdown of WWP1 in PC3

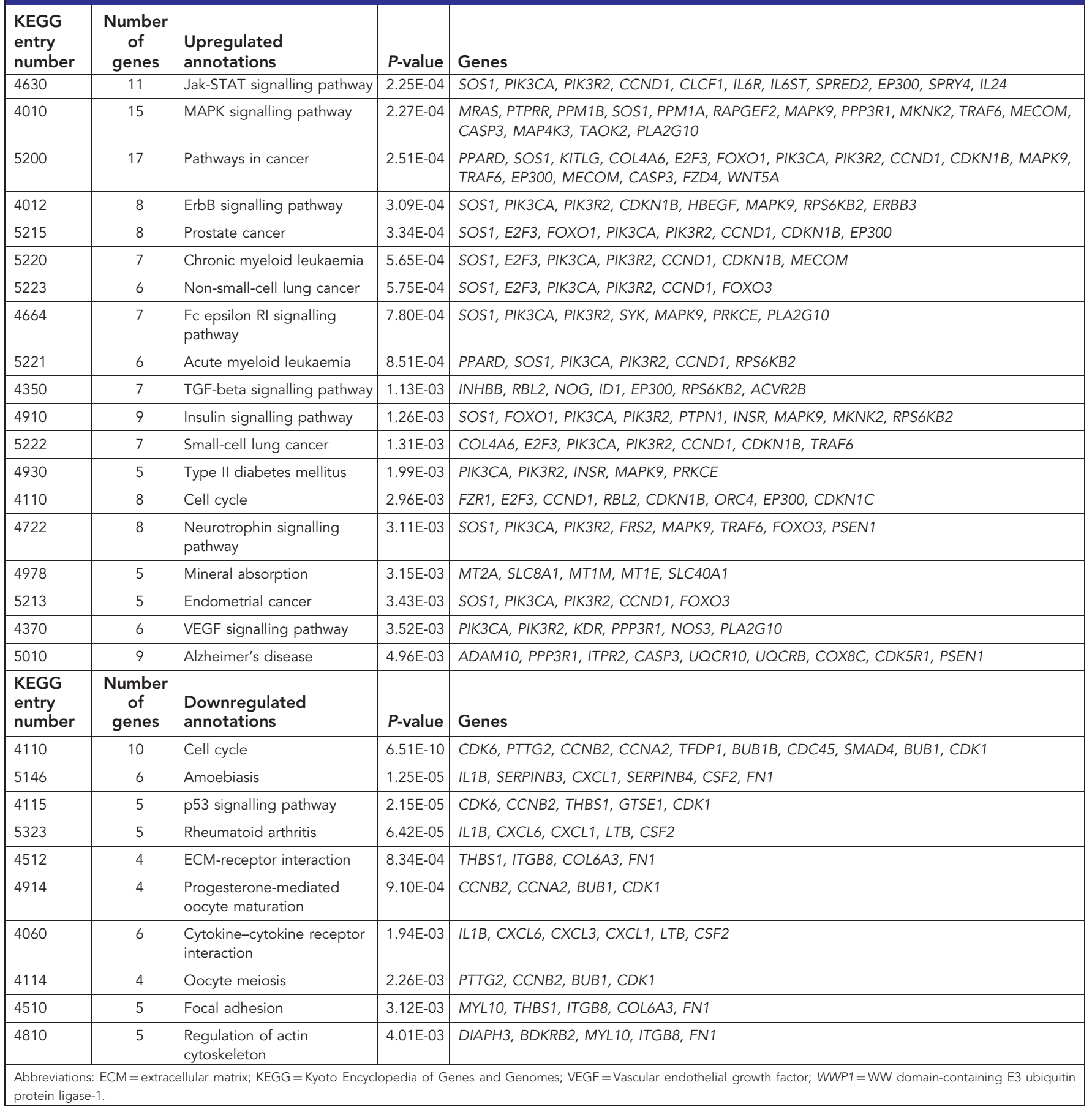

regions containing $\mathrm{CpG}$ islands is closely linked with gene silencing in cancer cells. Recent study showed that miR-452-miR-224 locus was downregulated in $\mathrm{PCa}$ compared with nonmalignant prostate tissue specimens. Downregulation of these miRNAs were associated with frequent aberrant promoter hypermethylation (Kristensen et al, 2014). Furthermore, GABRE as $m i R-452$ and $m i R-224$ host gene was silenced by aberrant promoter hypermethylation, and methylation status of this region was a useful biomarker for biochemical recurrence after radical prostatectomy (Kristensen et al, 2014). However, another group demonstrated the oncogenic function of $m i R-452$ in hepatocellular carcinoma targeting CDKN1B (Zheng et al, 2014). Likewise, miR-452 has been shown to be upregulated in advanced melanoma, thereby promoting the epithelial-mesenchymal transition (Knoll et al, 2014). One of the mechanisms of $m i R-452$ upregulation in melanoma is induction by E2F1, which has been shown to directly activate the miR-224/452 cluster (Knoll et al, 2014). Therefore, investigation of the molecular mechanisms of transcriptional control of the miR-224/452 cluster is necessary in various types of cancer.

According to prior studies, the function of $m i R-452$ varies greatly depending on the type of cancer. $m i R-452$ may have opposing roles in different types of cancer by targeting different pathways or cancer-associated genes. We narrowed down putative candidate genes of $m i R-452$ regulation to 10 genes in this study, and we focused on WWP1 and performed further analysis. As for other candidate genes of $m i R-452$ regulation, the functional significance of PCa is still unclear. Among them, GNA12 as a member of G-proteins is reported to contribute to cancer cell invasiveness (Rasheed et al, 2013). Aberrant G-protein-coupled 
receptors (GPCRs)-mediated signal enhanced cancer cell progression and aggressiveness, and GPCR signal primarily through heterotrimeric G-proteins $(\mathrm{G} \alpha, \mathrm{G} \beta$, and $\mathrm{G} \gamma)$. Upregulation of GNA12/13 were involved in aggressiveness and observed in advanced cancer tissues (Kelly et al, 2006; Rasheed et al, 2013). HMGB3 contains one or more high mobility group DNA-binding motifs, and overexpression of HMGB3 was reported in several cancers (Li et al, 2015). Interestingly, HMGB3 was direct regulation of $m i R-205$ in breast cancer (Elgamal et al, 2013). Our recent study demonstrated that miR-205 act as a tumour-suppressive miRNA in $\mathrm{PCa}$ cells through targeting centromere protein-F (Nishikawa et al, 2015). These facts suggest that the putative target gene list for $m i R$ 452 contains important oncogenic genes involved in $\mathrm{PCa}$ pathogenesis. In this study, we showed that WWP1 was a direct target of miR-452 and that knockdown of WWP1 significantly inhibited cancer cell proliferation, migration, and invasion in $\mathrm{PCa}$ cells. WWP1 is highly conserved among different animals and is ubiquitously expressed in many tissues (Zhi and Chen, 2012). Accumulating evidence suggests that E3 ubiquitin ligases play important roles in cancer development (Chen and Matesic, 2007; Zou et al, 2015). Overexpression of WWP1 was observed in breast and PCa (Chen et al, 2007; Zhou et al, 2012). Furthermore, significantly higher expression of WWP1 in PCa bone metastasis has been reported (Wang et al, 2014). Previous studies have indicated that overexpression of the mRNA and protein levels of WWP1 is significantly correlated with gene copy number gains in both types of cancers (Chen et al, 2007; Zhou et al, 2012), suggesting that WWP1 acts as an oncogene in these cancers. Interestingly, WWP1 was located on the human chromosome 8q21 region, which frequently displays gain of copy numbers in human cancers, including breast cancer and PCa (Byrne et al, 2012). Our previous study showed that tumour protein D52 (TPD52) located on chromosome 8q21 region was direct regulation of tumoursuppressive miR-224 in PCa cells (Goto et al, 2014b). A number of studies have reported that human chromosome 8q21.11-8q21.3 regions were frequently amplified in various cancers, including PCa (Byrne et al, 2012). Previous studies of PCa cells showed that TPD52 containing region was amplified and expression of TPD52 was highly elevated in cancer tissues (Rubin et al, 2004). Amplified genome regions are increasingly considered as targets of cancer therapy. Interestingly, TPD52 and WWP1 were located in this region, indicating that novel cancer pathways mediated by these responsible genes might be highlighted as PCa therapeutic targets.

WWP1 targets and ubiquitinates a variety of cancer-related proteins, including p53, p63, and Smad4, in several cancers (Moren et al, 2005; Laine and Ronai, 2007; Li et al, 2008). In hepatocellular carcinoma cells, silencing of WWP1 expression promotes cleavage of caspase 3 protein and expression of p53; these events suppress cell growth and promote apoptosis in cancer cells (Cheng et al, 2014). Another study showed that WWP1 increases the stabilisation of p53 protein in the cytoplasm and decreases p53 transcriptional activity (Laine and Ronai, 2007).

Interestingly, several studies have indicated that WWP1 acts as a regulator of receptor signalling in cancer cells. For example, WWP1 enhances ErbB2 and EGF receptor signalling through regulating ring finger protein 11 (RNF11), a negative regulator of these receptors (Chen et al, 2008). TGF-b receptor type 1 is degraded by WWP1 ubiquitination, and these events cause inhibition of TGF-b signalling (Komuro et al, 2004; Chen et al, 2007). Moreover, other studies have suggested that WWP1 interacts with ezrin and is involved in MET signalling. The MET receptor and its ligand, hepatocyte growth factor, have important effects on normal epithelial cells and cancer cells (Karamouzis et al, 2009; Gherardi et al, 2012). Ezrin is thought to be involved in several signalling pathways, such as cell adhesion to the extracellular matrix and receptor tyrosine-kinase signalling (Geissler et al, 2013; Goni et al, 2014; Oneyama et al, 2015).
Overexpression of ezrin has been observed in several types of cancers (Li et al, 2015; Ren et al, 2015; Singh et al, 2016). Thus, interaction of WWP1 with ezrin activates MET signalling, playing a pivotal role in cancer cell progression and metastasis.

In this study, we identified WWP1-mediated cancer pathways by using genome-wide gene expression analysis of $s i$-WWP1 transfected cells. Our data showed that several pathways were involved in WWP1 downstream pathways, such as the 'TGF-beta signalling pathway', 'ECM-receptor interaction', 'cell adhesion molecules', 'focal adhesion', and 'regulation of actin cytoskeleton'. The identification of these novel molecular pathways and targets mediated by the miR-452/WWP1 axis may lead to a better understanding of PCa progression and metastasis.

\section{CONCLUSIONS}

Downregulation of $m i R-452$ was validated in PCa clinical specimens, and this miRNA was shown to function as a tumour suppressor in PCa cells. Expression of miR-452 predicted a short duration of progression to CRPC. To the best of our knowledge, this is the first report demonstrating that tumour-suppressive $m i R$ 452 directly targeted WWP1. Moreover, WWP1 was upregulated in PCa clinical specimens and contributed to cancer cell invasion, indicating that this target functioned as an oncogene. The identification of novel molecular pathways and targets regulated by the miR-452/WWP1 axis may lead to a better understanding of $\mathrm{PCa}$ progression and metastasis.

\section{ACKNOWLEDGEMENTS}

This study was supported by Futaba Electronics Memorial Foundation, the KAKENHI, grant numbers (C) 26462430, (C) 15K10801, (B) 15K20071, and (B) 25293333.

\section{CONFLICT OF INTEREST}

The authors declare no conflict of interest.

\section{REFERENCES}

Attard G, Parker C, Eeles RA, Schroder F, Tomlins SA, Tannock I, Drake CG, de Bono JS (2016) Prostate cancer. Lancet 387: 70-82.

Bartel DP (2004) MicroRNAs: genomics, biogenesis, mechanism, and function. Cell 116: 281-297.

Bartel DP (2009) MicroRNAs: target recognition and regulatory functions. Cell 136: 215-233.

Byrne JA, Chen Y, Martin La Rotta N, Peters GB (2012) Challenges in identifying candidate amplification targets in human cancers: chromosome 8q21 as a case study. Genes Cancer 3: 87-101.

Chen C, Matesic LE (2007) The Nedd4-like family of E3 ubiquitin ligases and cancer. Cancer Metastasis Rev 26: 587-604.

Chen C, Sun X, Guo P, Dong XY, Sethi P, Zhou W, Zhou Z, Petros J, Frierson Jr HF, Vessella RL, Atfi A, Dong JT (2007) Ubiquitin E3 ligase WWP1 as an oncogenic factor in human prostate cancer. Oncogene 26: 2386-2394.

Chen C, Zhou Z, Liu R, Li Y, Azmi PB, Seth AK (2008) The WW domain containing E3 ubiquitin protein ligase 1 upregulates ErbB2 and EGFR through RING finger protein 11. Oncogene 27: 6845-6855.

Cheng Q, Cao X, Yuan F, Li G, Tong T (2014) Knockdown of WWP1 inhibits growth and induces apoptosis in hepatoma carcinoma cells through the activation of caspase 3 and p53. Biochem Biophys Res Commun 448: 248-254.

Crawford ED, Higano CS, Shore ND, Hussain M, Petrylak DP (2015) Treating patients with metastatic castration resistant prostate cancer: a comprehensive review of available therapies. J Urol 194: 1537-1547. 
Elgamal OA, Park JK, Gusev Y, Azevedo-Pouly AC, Jiang J, Roopra A, Schmittgen TD (2013) Tumor suppressive function of mir-205 in breast cancer is linked to HMGB3 regulation. PLoS One 8: e76402.

Friedman RC, Farh KK, Burge CB, Bartel DP (2009) Most mammalian mRNAs are conserved targets of microRNAs. Genome Res 19: 92-105.

Fuse M, Kojima S, Enokida H, Chiyomaru T, Yoshino H, Nohata N, Kinoshita T, Sakamoto S, Naya Y, Nakagawa M, Ichikawa T, Seki N (2012) Tumor suppressive microRNAs (miR-222 and miR-31) regulate molecular pathways based on microRNA expression signature in prostate cancer. J Hum Genet 57: 691-699.

Garzon R, Calin GA, Croce CM (2009) MicroRNAs in Cancer. Annu Rev Med 60: $167-179$.

Geissler KJ, Jung MJ, Riecken LB, Sperka T, Cui Y, Schacke S, Merkel U, Markwart R, Rubio I, Than ME, Breithaupt C, Peuker S, Seifert R, Kaupp UB, Herrlich P, Morrison H (2013) Regulation of Son of sevenless by the membrane-actin linker protein ezrin. Proc Natl Acad Sci USA 110: 20587-20592.

Gherardi E, Birchmeier W, Birchmeier C, Vande Woude G (2012) Targeting MET in cancer: rationale and progress. Nat Rev Cancer 12: 89-103.

Goni GM, Epifano C, Boskovic J, Camacho-Artacho M, Zhou J, Bronowska A, Martin MT, Eck MJ, Kremer L, Grater F, Gervasio FL, Perez-Moreno M, Lietha D (2014) Phosphatidylinositol 4,5-bisphosphate triggers activation of focal adhesion kinase by inducing clustering and conformational changes. Proc Natl Acad Sci USA 111: E3177-E3186.

Goto Y, Kojima S, Nishikawa R, Enokida H, Chiyomaru T, Kinoshita T, Nakagawa M, Naya Y, Ichikawa T, Seki N (2014a) The microRNA-23b/ 27b/24-1 cluster is a disease progression marker and tumor suppressor in prostate cancer. Oncotarget 5: 7748-7759.

Goto Y, Kojima S, Nishikawa R, Kurozumi A, Kato M, Enokida H, Matsushita R, Yamazaki K, Ishida Y, Nakagawa M, Naya Y, Ichikawa T, Seki N (2015a) MicroRNA expression signature of castration-resistant prostate cancer: the microRNA-221/222 cluster functions as a tumour suppressor and disease progression marker. $\mathrm{Br} J$ Cancer 113: 1055-1065.

Goto Y, Kurozumi A, Enokida H, Ichikawa T, Seki N (2015b) Functional significance of aberrantly expressed microRNAs in prostate cancer. Int J Urol 22: 242-252.

Goto Y, Nishikawa R, Kojima S, Chiyomaru T, Enokida H, Inoguchi S, Kinoshita T, Fuse M, Sakamoto S, Nakagawa M, Naya Y, Ichikawa T, Seki N (2014b) Tumour-suppressive microRNA-224 inhibits cancer cell migration and invasion via targeting oncogenic TPD52 in prostate cancer. FEBS Lett 588: 1973-1982.

Heidenreich A, Bastian PJ, Bellmunt J, Bolla M, Joniau S, van der Kwast T, Mason M, Matveev V, Wiegel T, Zattoni F, Mottet N (2014a) EAU guidelines on prostate cancer. part 1: screening, diagnosis, and local treatment with curative intent-update 2013. Eur Urol 65: 124-137.

Heidenreich A, Bastian PJ, Bellmunt J, Bolla M, Joniau S, van der Kwast T, Mason M, Matveev V, Wiegel T, Zattoni F, Mottet N (2014b) EAU Guidelines on Prostate Cancer. Part II: treatment of advanced, relapsing, and castration-resistant prostate cancer. Eur Urol 65: 467-479.

Iorio MV, Croce CM (2012) MicroRNA dysregulation in cancer: diagnostics, monitoring and therapeutics. A comprehensive review. EMBO Mol Med 4: 143-159.

Karamouzis MV, Konstantinopoulos PA, Papavassiliou AG (2009) Targeting MET as a strategy to overcome crosstalk-related resistance to EGFR inhibitors. Lancet Oncol 10: 709-717.

Kelly P, Stemmle LN, Madden JF, Fields TA, Daaka Y, Casey PJ (2006) A role for the G12 family of heterotrimeric G proteins in prostate cancer invasion. J Biol Chem 281: 26483-26490.

Knoll S, Furst K, Kowtharapu B, Schmitz U, Marquardt S, Wolkenhauer O, Martin H, Putzer BM (2014) E2F1 induces miR-224/452 expression to drive EMT through TXNIP downregulation. EMBO Rep 15: $1315-1329$.

Kojima S, Chiyomaru T, Kawakami K, Yoshino H, Enokida H, Nohata N, Fuse M, Ichikawa T, Naya Y, Nakagawa M, Seki N (2012) Tumour suppressors miR-1 and miR-133a target the oncogenic function of purine nucleoside phosphorylase (PNP) in prostate cancer. $\mathrm{Br} J$ Cancer 106: 405-413.

Kojima S, Enokida H, Yoshino H, Itesako T, Chiyomaru T, Kinoshita T, Fuse M, Nishikawa R, Goto Y, Naya Y, Nakagawa M, Seki N (2014) The tumorsuppressive microRNA-143/145 cluster inhibits cell migration and invasion by targeting GOLM1 in prostate cancer. J Hum Genet 59: 78-87.

Komuro A, Imamura T, Saitoh M, Yoshida Y, Yamori T, Miyazono K, Miyazawa K (2004) Negative regulation of transforming growth factor-beta (TGF-beta) signaling by WW domain-containing protein 1 (WWP1). Oncogene 23: 6914-6923.

Kristensen H, Haldrup C, Strand S, Mundbjerg K, Mortensen MM, Thorsen K, Ostenfeld MS, Wild PJ, Arsov C, Goering W, Visakorpi T, Egevad L, Lindberg J, Gronberg H, Hoyer S, Borre M, Orntoft TF, Sorensen KD (2014) Hypermethylation of the GABRE miR-452 miR224 promoter in prostate cancer predicts biochemical recurrence after radical prostatectomy. Clin Cancer Res 20: 2169-2181.

Kurozumi A, Goto Y, Matsushita R, Fukumoto I, Kato M, Nishikawa R, Sakamoto S, Enokida H, Nakagawa M, Ichikawa T, Seki N (2016) Tumorsuppressive microRNA-223 inhibits cancer cell migration and invasion by targeting ITGA3/ITGB1 signaling in prostate cancer. Cancer Sci 107: $84-94$.

Laine A, Ronai Z (2007) Regulation of p53 localization and transcription by the HECT domain E3 ligase WWP1. Oncogene 26: 1477-1483.

Lewis BP, Burge CB, Bartel DP (2005) Conserved seed pairing, often flanked by adenosines, indicates that thousands of human genes are microRNA targets. Cell 120: 15-20.

Li J, Wei K, Yu H, Jin D, Wang G, Yu B (2015) Prognostic value of ezrin in various cancers: a systematic review and updated meta-analysis. Sci Rep 5: 17903.

Li M, Cai Y, Zhao H, Xu Z, Sun Q, Luo M, Gu L, Meng M, Han X, Sun H (2015) Overexpression of HMGB3 protein promotes cell proliferation, migration and is associated with poor prognosis in urinary bladder cancer patients. Tumour Biol 36: 4785-4792.

Li Y, Zhou Z, Chen C (2008) WW domain-containing E3 ubiquitin protein ligase 1 targets p63 transcription factor for ubiquitin-mediated proteasomal degradation and regulates apoptosis. Cell Death Differ 15: 1941-1951.

Liu L, Chen K, Wu J, Shi L, Hu B, Cheng S, Li M, Song L (2013) Downregulation of miR-452 promotes stem-like traits and tumorigenicity of gliomas. Clin Cancer Res 19: 3429-3438.

Mendell JT (2008) miRiad roles for the miR-17-92 cluster in development and disease. Cell 133: 217-222.

Moren A, Imamura T, Miyazono K, Heldin CH, Moustakas A (2005) Degradation of the tumor suppressor Smad4 by WW and HECT domain ubiquitin ligases. J Biol Chem 280: 22115-22123.

Nishikawa R, Goto Y, Kurozumi A, Matsushita R, Enokida H, Kojima S, Naya Y, Nakagawa M, Ichikawa T, Seki N (2015) MicroRNA-205 inhibits cancer cell migration and invasion via modulation of centromere protein $\mathrm{F}$ regulating pathways in prostate cancer. Int J Urol 22: 867-877.

Oneyama C, Yoshikawa Y, Ninomiya Y, Iino T, Tsukita S, Okada M (2015) Fer tyrosine kinase oligomer mediates and amplifies Src-induced tumor progression. Oncogene 35: 501-512.

Rasheed SA, Teo CR, Beillard EJ, Voorhoeve PM, Casey PJ (2013) MicroRNA182 and microRNA-200a control G-protein subunit alpha-13 (GNA13) expression and cell invasion synergistically in prostate cancer cells. J Biol Chem 288: 7986-7995.

Ren L, Mendoza A, Zhu J, Briggs JW, Halsey C, Hong ES, Burkett SS, Morrow J, Lizardo MM, Osborne T, Li SQ, Luu HH, Meltzer P, Khanna C (2015) Characterization of the metastatic phenotype of a panel of established osteosarcoma cells. Oncotarget 6: 29469-29481.

Rubin MA, Varambally S, Beroukhim R, Tomlins SA, Rhodes DR, Paris PL, Hofer MD, Storz-Schweizer M, Kuefer R, Fletcher JA, Hsi BL, Byrne JA, Pienta KJ, Collins C, Sellers WR, Chinnaiyan AM (2004) Overexpression, amplification, and androgen regulation of TPD52 in prostate cancer. Cancer Res 64: 3814-3822.

Siegel RL, Miller KD, Jemal A (2015) Cancer statistics, 2015. CA Cancer J Clin 65: 5-29.

Singh R, Kapur N, Mir H, Singh N, Lillard Jr JW, Singh S (2016) CXCR6CXCL16 axis promotes prostate cancer by mediating cytoskeleton rearrangement via Ezrin activation and alphavbeta3 integrin clustering. Oncotarget 7: 7343-7353.

Wang Z, Wang J, Li X, Xing L, Ding Y, Shi P, Zhang Y, Guo S, Shu X, Shan B (2014) Bortezomib prevents oncogenesis and bone metastasis of prostate cancer by inhibiting WWP1, Smurf1 and Smurf2. Int J Oncol 45: 1469-1478.

Zheng Q, Sheng Q, Jiang C, Shu J, Chen J, Nie Z, Lv Z, Zhang Y (2014) MicroRNA-452 promotes tumorigenesis in hepatocellular carcinoma by targeting cyclin-dependent kinase inhibitor 1B. Mol Cell Biochem 389: $187-195$.

Zhi X, Chen C (2012) WWP1: a versatile ubiquitin E3 ligase in signaling and diseases. Cell Mol Life Sci 69: 1425-1434. 
Zhou Z, Liu R, Chen C (2012) The WWP1 ubiquitin E3 ligase increases TRAIL resistance in breast cancer. Int J Cancer 130: 1504-1510.

Zou X, Levy-Cohen G, Blank M (2015) Molecular functions of NEDD4 E3 ubiquitin ligases in cancer. Biochim Biophys Acta 1856: 91-106.
This work is published under the standard license to publish agreement. After 12 months the work will become freely available and the license terms will switch to a Creative Commons AttributionNonCommercial-Share Alike 4.0 Unported License.

Supplementary Information accompanies this paper on British Journal of Cancer website (http://www.nature.com/bjc). 